\title{
The Roles of Positive and Negative Evidence in the Development of the English Present Progressive Structure
}

\author{
Sarah Al-Maghrabi \\ English Language Institute, King Abdulaziz University \\ PO Box 80200, Jeddah 21589, Saudi Arabia \\ Tel: 96-612-640-0000Ｅ-mail: salmaghrabi0035@stu.kau.edu.sa \\ Mona Sabir (Corresponding author) \\ English Language Institute, King Abdulaziz University \\ PO Box 80200, Jeddah 21589, Saudi Arabia \\ Tel: 96-612-640-0000Ｅ-mail: msabir@kau.edu.sa
}

Received: August 19, 2019 Accepted: August 30, 2019 Published: September 1, 2019

doi:10.5296/ijele.v7i2.15384 URL: https://doi.org/10.5296/ijele.v7i2.15384

\begin{abstract}
The type of linguistic evidence necessary for ultimate L2 attainment has been a major topic of debate. This research investigates the role of negative vs. positive evidence in the acquisition of the affirmative and negative present progressive structures. Following a quasi-experimental design, 49 Saudi EFL learners were divided into three groups: Control Group ( $n=13)$, Negative Evidence group $(n=15)$, and Positive Evidence group $(n=21)$. It was hypothesized that negative evidence would be more effective for the acquisition of the present progressive structure than positive evidence, to the point that a significant difference would result between the performance of the two experimental groups. The participants took a pre-test, after which they were given classroom intervention sessions on the use of the English present progressive structure. They then took a post-test. The results show significant differences in the performance of the experimental groups compared to the control group. However, there was no statistical difference between the two experimental groups. Thus, the research supports the importance of the role of negative evidence in teaching L2 when paired with positive evidence. We outline pedagogical implications for further research to determine the extent to which the two types of evidence can be blended in English language classrooms.
\end{abstract}

Keywords: Positive evidence, negative evidence, present progressive, classroom experiment 


\section{Introduction}

The present progressive structure is a structure that usually poses difficulty for L2 learners of English (Zhiri, 2017). Learners often struggle to grasp the target meaning or function of this structure. Additionally, traditional classroom instruction often fails to capture a linguistically accurate representation of this structure, which leads to non-target-like performance by L2 learners.

When it comes to L2 classroom input, the type of linguistic evidence necessary for ultimate L2 attainment has been a major topic of debate (e.g. Bowerman, 1988; White, 1991; Bruton, 2000; Chouinard \& Clark, 2003; Bardovi-Harlig \& Sprouse, 2018). According to Long (1996), second language acquisition has two major types of input: positive and negative evidence. Positive evidence is the type of input that language learners receive in a natural linguistic environment. It can be provided to second language learners as authentic input, and it consists of correct grammatical utterances in the target language. In contrast, negative evidence provides language learners with information about what the target language does not permit. Negative evidence involves providing language learners with explicit grammar instruction and examples of ungrammatical sentences. The majority of EFL teachers agree on the importance and the effectiveness of using both positive and negative evidence in EFL classrooms (Strapp et al., 2011; Jiang and Yi, 2014). However, disagreement persists regarding what type of evidence should be emphasized as the major input in L2 classrooms.

The present paper presents a classroom experimental study that aims to investigate the effectiveness of using negative evidence vs. positive evidence on the acquisition of the present progressive structure in EFL classrooms. The paper starts with contrastive analysis of the present progressive structure in English vs. Arabic. Subsequently, an overview of the major issues in the field is presented. The details of the experimental study follow. Finally, the findings and their pedagogical implications are discussed.

\section{The Present Progressive Structure in English vs. Arabic}

English and Arabic have different tense-aspect systems. While English has many classes of tense and aspect, Arabic has only two aspects: the perfect, called 'al madi', which refers to complete actions, and the imperfect, called 'al modarie', which refers to incomplete ones. Therefore, it has been found that Arab learners of English often overuse the simple aspects in their L2 production (Zhiri, 2017). In short, because the present progressive structure differs in Arabic and English, it is an especially problematic area for Arab learners of English. First, Arab learners may negatively transfer incorrect structures to English due to first language interference. In examining the tense and aspect dissimilarity between English and Arabic, Alsalmi (2013) found that in several cases, L2 learners tend to transfer language knowledge from their native language to the L2, resulting in linguistic interference. Furthermore, Zhiri (2017) found that Arab learners tend to associate the present progressive with one context of use only, which is actions taking place at the time of speaking (see Example 1); other contexts of present progressive use, such as when it is used to describe a changing situation, 
are usually disregarded (see Example 2).

\section{Example (1)}

Emily is doing her homework now.

\section{Example (2)}

Your mathematical skills are improving.

Thus, the difficulty that Arab learners encounter when learning the progressive aspect may be attributed to the lack of a one-to-one morphological correspondence between the present progressive tenses in English and Arabic (Alsalmi, 2013). Alsalmi (2013) provided a description of the contrast of tense and aspect between English and Arabic from a structural point of view based on Lado's (1957) idea that a grammatical function can be represented differently in different languages. That is, the same form of the verb can be functionally different even within the same language. Table 1 below shows the contrast between English and Arabic in the present progressive structure.

Table 1. The contrast between English and Arabic in the present progressive structure (taken from Alsalmi, 2013, p. 8)

\begin{tabular}{|l|l|l|}
\hline The Linguistic Structure & \multicolumn{1}{|c|}{ English } & \multicolumn{1}{c|}{ Arabic } \\
\hline Present Progressive & $\begin{array}{l}\text { 1. He is watching TV. (action } \\
\text { in progress). }\end{array}$ & $\begin{array}{l}\text { 1. Different: present progressive is } \\
\text { indicated by: } \\
\text { * present simple: } \\
\text { Yushahidu a-telfaza } \\
\text { He watches TV } \\
\text { or } \\
\text { * active participle with no finite form: } \\
\text { Huwa aatin nahwi. } \\
\text { He is coming towards me. }\end{array}$ \\
& & $\begin{array}{l}\text { 2. Different: future simple forms are } \\
\text { used } \\
\text { 2. They are playing } \\
\text { tomorrow. (future) }\end{array}$ \\
& $\begin{array}{l}\text { (for plans and arrangements): } \\
\text { sa-/sawfa yalaabuna gadan. } \\
\text { 'They will play tomorrow'. }\end{array}$ \\
& &
\end{tabular}


The present investigation endeavours to see if negative evidence might help L2 Arab learners overcome this difficulty and adjust to the equivalent parameters in forming English present progressive structure sentences.

\section{Linguistics Evidence in SLA}

The distinction between positive and negative evidence in SLA is crucial to developing an understanding of the difference between L1 and L2 development and to discovering what implications this difference might have for second/foreign language classrooms. Positive evidence is usually defined as "utterances in the input" (White, 1991, p. 134). Conversely, negative evidence is defined as "information about which strings of words are not grammatical sentences" (Marcus, 1993, p. 53). Generative language acquisition theorists argue that in L1 acquisition, Universal Grammar parameters are triggered by input that mainly depends on positive evidence (Krashen, 1982). However, White (1991) found that L2 learners' incorrect assumptions, when based on positive evidence, led to the consideration of the role of negative evidence and thus to the conclusion that L2 acquisition often relies on both types of linguistic evidence. Furthermore, White (1991) argued that negative evidence may play a more significant role in L2 than in L1.

In SLA literature, we find that researchers usually have two opposing views when it comes to the role of linguistic evidence in L2 development. Opponents of the use of negative evidence in L2 classrooms (e.g. Schwartz, 1993) have argued that negative evidence is not essential in SLA. The claim is that, as in L1, only positive evidence can affect the structure of the interlanguage grammar. Schwartz (1993) further indicated that negative evidence results in a type of knowledge that cannot be equated with linguistic competence. In this regard, Schwartz and Gubala-Ryzak (1992) conducted a study that justified the limited use of negative evidence as a source of knowledge about verb movement. In their study, Schwartz and Gubala-Ryzak concluded that negative evidence has no significant role in interlanguage grammar as the inability to learn verb movement was actually affected by first language transfer. Additionally, they found that the use of negative evidence in such cases might reinforce inaccuracies caused by the transfer of the L1.

Proponents of the use of negative evidence argue that negative evidence facilitates L2 development. In this regard, Carroll and Swain (1993) stated that "In theoretical terms it is imperative to provide explicit content to a theory of language learning, to show how the development of knowledge of specific linguistic phenomena could be explained by the basic mechanisms of induction" (p. 358). This argument calls for the implementation of explicit content/negative evidence since the type of input may affect how the linguistic knowledge underlying existing linguistic structures can be restructured. Several studies have supported the role of negative evidence for the development of both L1 and L2. For example, Strapp, Bleakney, Helmick, and Tonkovich (2008) compared positive and negative evidence in the acquisition of irregular L1 nouns and verbs among children aged three, four, and five years old. The findings emphasized the importance of using negative evidence in L1 learning, as the negative evidence group outperformed the positive evidence group in grammatical 
development. In comparing the field of first language acquisition to the field of second language acquisition, Abolhasanpour and Jabbari (2014) highlighted the importance of negative evidence availability for second language learners as well. Moreover, they emphasized the role of negative evidence in providing different opportunities for learners to recognize ill-formed sentences. Abolhasanpour and Jabbari's study further indicated that negative evidence is actually needed to reset a language parameter to its L2 equivalent. Such results may lead to the conclusion that negative evidence can be equally as effective as positive evidence in $\mathrm{L} 2$ acquisition.

Early classroom intervention researchers include White (1991), who argued that providing French learners with form-focused classroom instruction that includes negative evidence helps the learners better understand the principles of adverb placement in the English language than does providing positive evidence alone. In English, unlike French, an adverb is not grammatically allowed to occur between a verb and its direct object. In her experimental study, White recruited two groups of 11- and 12-year-old francophone learners of English. The first group received explicit instruction in adverb placement while the second group received instruction on question formation. Both groups were pre-tested prior to the instruction period and immediately post-tested after the instructional period. Participants also took a delayed post-test five weeks after instruction had ended, and some of them were tested again a year after the experiment had taken place. The results showed that the group that received positive and negative evidence on adverb placement learned that adverbs cannot occupy a position between the verb and object. However, White's study showed results in favour of negative evidence only in the immediate post-test. The follow-up results showed no advantage of instruction, suggesting that the knowledge is not retained in the long term.

Furthermore, Iwashita (2003) discussed the short-term effects of positive evidence paired with implicit negative feedback on 55 Australian learners of Japanese as a second language. In this study, Iwashita investigated conversational grammatical development through task-based interactions. He focused on the acquisition of two grammar aspects: the Japanese locative-initial construction and the verb morpheme te-form verb. The findings showed that both positive evidence and negative feedback helped the participants in short-term acquisition of the te-from verb, while only positive evidence was effective in the acquisition of locative-initial.

Thus, the two important remaining questions are as follows: What is the appropriate amount of each type of evidence required for L2 acquisition, and which type plays a more significant role in ultimate L2 attainment? Jiang and Yi (2014) pointed out that both positive and negative evidence are equally fundamental for L2 acquisition. Yet, more investigation is needed to ascertain the validity of this assumption. Following the lines of White's (1991) research, we take the position that positive evidence is not enough to trigger development of the linguistic properties of the English present progressive aspect. That is, achieving target-like accuracy in using the present progressive structure requires classroom instruction that includes negative evidence. 


\section{Macrothink}

\section{Methodology}

\subsection{Participants}

The participants for this study were female Saudi foundation year students at King Abdulaziz University, Jeddah, Saudi Arabia. Participants were enrolled as elementary-level learners in a general English language course (level 101). They were divided into three groups: a Control Group which consisted of 13 students and was used as a benchmark to detect the change in the level of the experimental groups; the Negative Evidence Group which consisted of 15 students; and finally, the Positive Evidence Group, which consisted of 21 students. The participants' ages ranged between were between 17 and 21 years.

\subsection{Instrument}

The participants took a pen and a paper task that was given as a pre-test and as a post-test (with a change in the order of questions and variations in the composition of the sentences). The task included two sections: multiple-choice questions where the students had to choose the correct answer to complete the correct form for each sentence, and a grammaticality judgment task, where the students had to decide whether the given sentences were correct or incorrect (see Appendix 1 for the pre-test and Appendix 2 for the post-test).

\subsection{Research Procedure}

The study followed a quasi- experimental design. The participants took a pre-test that lasted for 30 minutes. Then, they were given classroom intervention for two sessions. Lastly, they took a post-test that also required 30 minutes to finish.

The intervention for this study was divided into two sessions given in two days. One of the researchers was responsible for the delivery of instruction on present progressive to the experimental groups. The control group did not receive any instruction on the present progressive structure and only took the pre-test and the post-test.

\subsection{Classroom Intervention}

In the first intervention session, the researcher separately taught present progressive affirmative and negative sentence formation to each experimental group. For the Positive Evidence Group, the researcher explained (by providing numerous correct examples on the use of the present progressive structure) in both affirmative and negative contexts. Instruction, worksheets, and activities on the use of this grammatical structure were also given to the students and were completed in pairs or in groups. For the Negative Evidence Group, the researcher explained the same grammar structure by providing students with not only the correct form of the affirmative and negative formations of the present progressive tense, but also by highlighting some ungrammatical formations of the structure and giving examples of 
possible mistakes that students might make while producing this structure. The instruction was also supported by the use of worksheets and activities on the present progressive structure, and students were provided with ill-formed sentences and were asked to underline the error(s) and give the correct answer(s).

In the second intervention session, the researcher reviewed the use of the present progressive structure and related it to time expressions which can be used with the structure. In the same manner, the researcher provided the Positive Evidence Group with numerous correct examples of time expressions used with the present progressive structure, while the Negative Evidence Group was exposed to examples of incorrect use of time expressions. Again, the two groups were given worksheets and activities to be completed in pairs or in groups for practice.

\section{Results}

A mixed between-within subjects' analysis of variance was conducted to analyse the impact of implementing two different types of evidence, positive and negative, on the participants' pre-test and post-test scores with regard to their production of the present progressive structure. By comparing the means of the three groups, we find no significant difference in the control group pre-test $(\mathrm{M}=4.15, \mathrm{SD}=1.463)$ and post-test $(\mathrm{M}=4.23, \mathrm{SD}=1.235)$, as expected. However, there was improvement shown by increases in the post-test means of the two experimental groups: Negative Evidence Group pre-test $(\mathrm{M}=4.53, \mathrm{SD}=1.685)$ and post-test $(\mathrm{M}=6.20, \mathrm{SD}=1.740)$ and the Positive Evidence Group pre-test $(\mathrm{M}=3.76, \mathrm{SD}=1.261)$ and post-test $(\mathrm{M}=5.67, \mathrm{SD}=2.331)$ (see Table 1 below for the details of the descriptive statistics).

Table 2. Descriptive Statistics (Means and Standard Deviation)

\begin{tabular}{|l|l|l|l|l|}
\hline & Groups & Mean & Std. Deviation & $\mathrm{N}$ \\
\hline Task Score Pre-test & Control Group & 4.15 & 1.463 & 13 \\
\cline { 2 - 5 } & $\begin{array}{l}\text { Negative Evidence } \\
\text { Group }\end{array}$ & 4.53 & 1.685 & 15 \\
\cline { 2 - 5 } & Positive Evidence group & 3.76 & 1.261 & 21 \\
\cline { 2 - 5 } & Total & 4.10 & 1.461 & 49 \\
\hline Task Score Post-test & Control Group & 4.23 & 1.235 & 13 \\
\cline { 2 - 5 } & $\begin{array}{l}\text { Negative Evidence } \\
\text { Group }\end{array}$ & 6.20 & 1.740 & 15 \\
\cline { 2 - 5 } & $\begin{array}{l}\text { Positive Evidence } \\
\text { Group }\end{array}$ & 5.67 & 2.331 & 21 \\
\cline { 2 - 5 } & Total & 5.45 & 2.032 & 49 \\
\hline
\end{tabular}




\section{Macrothink}

Figure 1 below represents the estimated marginal means of the differences between the three groups' scores on the pre-test and the post-test.

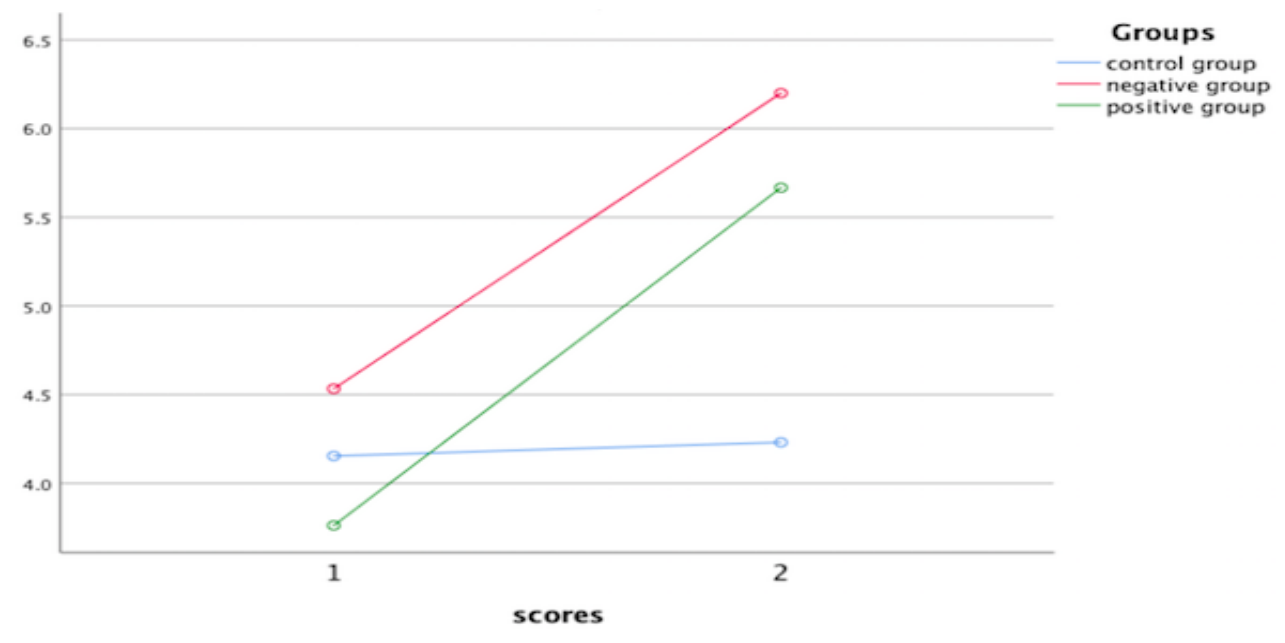

Figure 1. Pre-test and post-test estimated marginal means

The inferential results show that there was no significant difference between the experimental groups, Wilks' Lambda $=.85, F(2,46)=2.98 p=.06$, partial eta squared $=.11$. There was a substantial main effect for the difference between the pre-test and the post-test scores, Wilks' Lambda $=.76, F(1,46)=14.29, P<.001$, partial eta squared $=.23$, with experimental groups showing an improvement in statistical test scores between the pre-test and the post-test compared to the control group. The main effect comparing the two types of intervention between the three groups was not significant, $F(2,46)=2.89, p=.06$, partial eta squared $=.11$, suggesting no difference in the effectiveness of positive or negative evidence.

To summarize, the results report no significant differences between the two experimental groups, as both negative and positive evidence groups showed improvement on the post-test compared to the control. However, the two experimental groups outperformed the Control group in the post-test which suggests effectiveness of the intervention material. These results are discussed in detail in the next section.

\section{Discussion and Conclusion}

The aim of this study was to examine the effects of positive vs. negative evidence on the acquisition of the present progressive structure and its time expressions by Saudi EFL learners. The results have shown no significant differences between the two intervention groups, but both experimental groups' performance improved in the post-test compared to the control group regardless of the input type. Though not statistically significantly different, the Negative Evidence Group outperformed the Positive Evidence Group at the descriptive statistics level.

Looking back at what this research hypothesized earlier, namely that negative evidence is 
more effective than positive evidence when teaching present progressive structure, it is clear that the results obtained here do not support these assumptions. That is, when the two experimental groups' post-test scores were compared, there was no significant difference between them. However, the post-test scores of the experimental groups revealed an improvement in the participants' performance and a significant change when compared to pre-test scores.

Although there was no significant difference in the post-test scores between the experimental groups, the data obtained from the present study demonstrated the effectiveness of both negative and positive evidence. Looking closely at the improvements that are represented in the mean scores of the post-test, there was a slight difference between negative and positive evidence groups. A possible explanation for this, despite a noticeable increase in the negative group mean scores, may be the overlapping of positive evidence with negative evidence during the delivery of instruction to the Negative Evidence Group. As suggested by Abolhasanpour and Jabbari (2014), negative evidence helps L2 learners in resetting the target language parameter and makes them aware of the possible ungrammatical structures of any given linguistic structure. These findings also support Jiang and Yi's (2014) results regarding the efficacy of both types of evidences in L2 acquisition in that both linguistic evidences are essential in fostering and facilitating L2 development. These results reflect those of White (1991) who also confirmed the effectiveness of negative evidence through her study in which the adverb placement group that was instructed using negative and positive evidence outperformed the other group.

The lack of a significant difference between the two experimental groups supports what was predicted in the present study. Evidently, the present study's findings about the effectiveness of negative evidence contradict Schwartz and Gubala-Ryzak's (1992) conclusion that negative evidence is ineffective as an input for L2 learners and leads to learning inaccuracy. The improvement in the negative evidence group's performance on the post-test, suggests a fundamental role for this type of linguistic evidence in L2 development. By looking at the scores of the negative and the positive evidence groups, it is safe to assume that both types are effective as a means of knowledge acquisition, especially when they are frequently provided to L2 learners as discussed by Strapp et al. (2011). Further studies on these types of linguistic evidence should be undertaken to confirm these results.

The main goal of the current study was to investigate the effects of positive and negative linguistic evidence on L2 development of the English present progressive structure. The major limitation of the research was the short period of instruction due to time constraints. It would be more effective in future research to consider the roles of different types of linguistic evidence over a longer intervention period. Further research is required to determine the extent to which the two types of linguistic evidence should be introduced in EFL classrooms. Another major limitation is related to the gender of the participants. The study utilised female participants only. Therefore, the results cannot be generalised. Future research should utilise both genders in order to create a sample that is representative and reach results that can be generalisable. 


\section{References}

Abolhasanpour, F., \& Jabbari, A. A. (2014). The effect of negative and positive evidence on acquisition of quantifiers by Iranian EFL. International Journal of English Linguistics, 4(2), 46. https://doi.org/10.5539/ijel.v4n2p46

Alsalmi, M. (2013). Tense and aspect acquisition in L2 English by native speakers of Arabic. Arab World English Journal, 4(2).

Bardovi-Harlig, K., \& Sprouse, R. A. (2018). Negative versus positive transfer. The TESOL Encyclopedia of English Language Teaching, 1-6. https://doi.org/10.1002/9781118784235.eelt0084

Bowerman, M. (1988). The no negative evidence problem: How do children avoid constructing an overly general grammar? In V. A. Hawkins (Ed.), Explaining Language Universals. Oxford: Blackwell.

Bruton, A. (2000). What exactly are positive and negative evidence in SLA? RELC Journal, 31(2), 120-133. https://doi.org/10.1177/003368820003100206

Chouinard, M. M., \& Clark, E. V. (2003). Adult reformulations of child errors as negative evidence. Journal of Child Language, 30(3), 637-669. https://doi.org/10.1017/S0305000903005701

Iwashita, N. (2003). Negative feedback and positive evidence in task-based interaction: Differential effects on L2 development. Studies in Second Language Acquisition, 25(1), 1-36. https://doi.org/10.1017.S0272263103000019

Jiang, L., \& Yi, H. (2014). The effect of positive evidence and negative feedback on EFL learners' acquisition of the third person singular form. International Journal of English Linguistics, 4(6), 124. https://doi.org/10.5539/ijel.v4n6p124

Long, M. (1996). The role of the linguistic environment in second language acquisition. In W. Ritchie \& T. Bhatia (Eds.), Handbook of Second Language Acquisition. San Diego: Academic Press. https://doi.org/10.1111/b.9781405132817.2005. 00001.x

Marcus, G. F. (1993). Negative evidence in language acquisition. Cognition, 46, 53-85.

Schwartz, B. D. (1993). On explicit and negative data effecting and affecting competence and linguistic behavior. Studies in Second Language Acquisition, 15(2), 147-163. https://doi.org/10.1017/S0272263100011931

Schwartz, B. D., \& Gubala-Ryzak, M. (1992). Learnability and grammar reorganization in L2A: Against negative evidence causing the unlearning of verb movement. Interlanguage Studies Bulletin (Utrecht), 8(1), 1-38. https://doi.org/10.1177/026765839200800102

Strapp, C. M., Bleakney, D. M., Helmick, A. L., \& Tonkovich, H. M. (2008). Developmental differences in the effects of negative and positive evidence. First Language, 28(1), 35-53. https://doi.org/10.1177/0142723707084840 


\section{Macrothink}

International Journal of English Language Education ISSN 2325-0887 2019, Vol. 7, No. 2

White, L. (1991). Adverb placement in second language acquisition: Some effects of positive and negative evidence in the classroom. Interlanguage Studies Bulletin (Utrecht), 7(2), 133-161. https://doi.org/10.1177/0267658391007205

Zhiri, Y. (2017). The present progressive: A difficult aspect to learn - Evidence from the Moroccan EFL classroom. Arab World English Journal, 8(4), 401-411. 


\section{Appendix}

Appendix 1. Pre-test

Name:

UID:

Group:

Question (1)

Choose the correct answer:

1- Nahid is a book.

(reading - reads - read)

2- I can French.

(spoke - speak - speaking)

3- The students not listening. (are - is - am)

4- It is raining (now - later - yesterday)

5- She watch horror movies.

(don't - is - doesn't)

6- The kids (are play - are playing - plays)

7- I Korean drama.

(loves - love - loving)

8- I am my lunch.

(having - had - has)

Question (2)

Decide whether the following sentences are correct or incorrect:

1- I am leave now.

2- Do she listen to music?

3- Safi is walking at the moment.

4- The boy like football.

5- We are working on a project last night.

6- I can write short stories.

7- I am driving my car.

8- They aren't following.
(correct - incorrect)
(correct - incorrect)
(correct - incorrect)
(correct - incorrect)
(correct - incorrect)
(correct - incorrect)
(correct - incorrect)
(correct - incorrect) 
Appendix 2. Post-test

Name:

UID:

Group: (

Question (1)

Decide whether the following sentences are correct or incorrect:

1- I like fashion.

(correct - incorrect)

2- I am doing my homework.

(correct - incorrect)

3- I can write short stories.

(correct - incorrect)

4- Mike is working at the moment.

(correct - incorrect)

5- Do she listen to music?

(correct - incorrect)

6- I am studying now.

(correct - incorrect)

7- They aren't coming.

(correct - incorrect)

8- They are working on a project last night. (correct - incorrect)

Question (2)

Choose the correct answer:

1- $\quad$ Sarah is a meal.

(cooking - cooks - cook)

2- $\quad$ I Italian food.

(loves - love - loving)

3- I am my breakfast.

(eating - ate - eats)

4- The girls

(are playing - are play - plays)

5- I can't English.

(speaking - spoke - speak)

6- My father watching the news. (is - are - am)

7- It is now.

(raining - rained - rains)

8- I a student.

(is - are $-\mathrm{am}$ )

\section{Copyright Disclaimer}

Copyright for this article is retained by the author(s), with first publication rights granted to the journal.

This is an open-access article distributed under the terms and conditions of the Creative Commons Attribution license (http://creativecommons.org/licenses/by/3.0/). 